\title{
Mechanical Properties of Heat-AfFected ZONE OF High-STRENGTH STEEL WELDS
}

\author{
Ismar Hajro, Damir Hodžić \& Petar Tasić
}
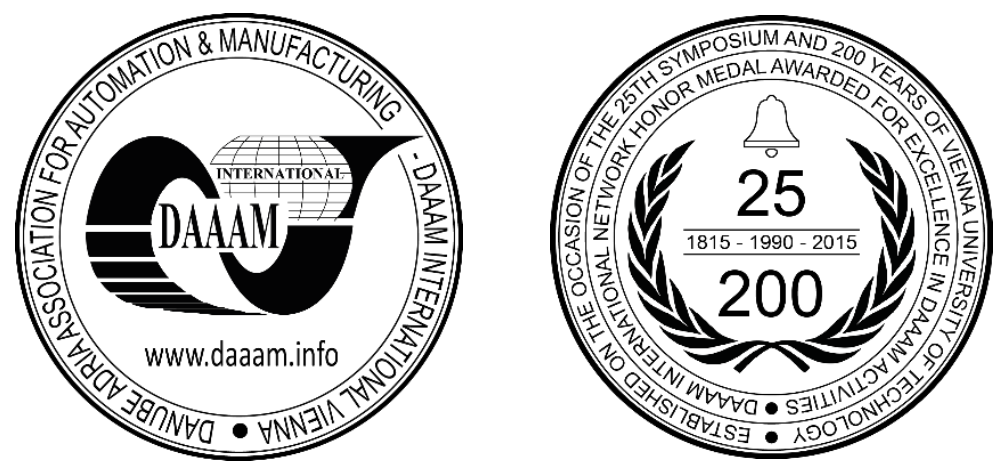

This Publication has to be referred as: Hajro, I[smar]; Hodzic, D[amir] \& Tasic, P[etar] (2017). Mechanical Properties of Heat-Affected Zone of High-Strength Steel Welds, Proceedings of the 28th DAAAM International Symposium, pp.0611-0616, B. Katalinic (Ed.), Published by DAAAM International, ISBN 978-3-902734-11-2, ISSN 1726-9679, Vienna, Austria

DOI: $10.2507 / 28$ th.daaam.proceedings.086

\begin{abstract}
Mechanical properties testing of structural steel welds are well known and standardized. Results of those testing are important information regarding evaluation and qualification of welding technologies. However, using only standardized testing it is not possible to evaluate the weakest part of welds; e.g. coarse-grained heat affected zone, where peak temperature over $1300{ }^{\circ} \mathrm{C}$ is reached during fusion welding. Such high temperatures have for consequence significant change and drop of some mechanical properties. Thus, it is important to perform some more sophisticated evaluation and prior preparation of test specimens. Actually, such prior preparation include welding thermo-cycle simulation on test specimen ready for standardized testing.

The paper present one combination of testing results, both standardised and sophisticated, for the purpose of more detailed review of mechanical properties of high-strength steel welds with nominal yield strength in the range of 690-890 MPa.

Detailed distribution across welds is presented including the following generalised mechanical properties: hardness, strength, toughness.

Significant drop of some mechanical properties is observed within coarse-grained heat affected zone, which may require particular attention within everyday engineering practice.
\end{abstract}

Keywords: mechanical properties; strength; hardness; toughness; high-strength steel welds; heat-affected zone; coarsegrained heat-affected zone

\section{Introduction}

Use of high-strength steels (HSS) in various structural application is beneficial due to the various reasons, while most of them are related generally to provision of lighter and energy saving structures $[1,2]$. While there is no some precise definition of HSS, they can be considered as one having yield strength equal or higher than $420 \mathrm{MPa}$. For the purpose of this paper two HSS are considered, in the range of nominal yield strength from 690 to $890 \mathrm{MPa}$, delivered in quenched and tempered (QT) condition.

Beside challenges which may be faced with application of various manufacturing technologies to HSS, such as banding or cutting; an application of welding technologies may become a particular challenge. This is mainly due to the two reasons: (1) loss of toughness; and (2) loss of crack resistance. Both problems are well known and particularly related 
to cooling time, $\mathrm{t}_{8 / 5}[\mathrm{~s}]$; which is principally opposite to a cooling rate, $\mathrm{v}_{\mathrm{c}}\left[{ }^{\circ} \mathrm{C} / \mathrm{s}\right]$. Actually, if fusion welding of $\mathrm{HSS}$ is performed with fast cooling rates (e.g. low t $8 / 5)$, there is a risk of microstructure hardening and further loss of cold crack resistance (e.g. hydrogen induced crack). Contrary, if welding is characterised with high $\mathrm{t}_{8 / 5}$, or slow cooling rates; there is a risk of microstructural grain coarsening within heat-affected zone (HAZ; Fig. 1a), following significant loss of toughness. Such generalised concept is well known, and it is one of primary concerns while welding HSS. Therefore, it is important to follow recommended $t_{8 / 5}$; which is mostly found within HSS manufacturer's specification. In addition,

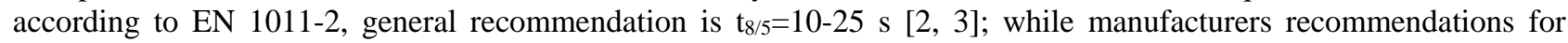
S690QL and S890QL are $t_{8 / 5}=5-15(20)$ s $[7,8]$.

Another concern may be related to real welds, which must be qualified by standard procedures (e.g. according to ISO 15614-1 or ASME BPVC Sec.IX; etc.); which consist of standardised testing of mechanical properties, including surface and volumetric non-destructive tests (NDT). The qualification means that predicted welding technology parameters are set well to finally provide sound and acceptable welded joints in production. Thus, a test parts of sufficient size are welded, following the sampling of test specimens for further mechanical and technological testing [4, 5].

Somehow, such requirements may be achieved; and overall welding technology may become qualified. However, such approach may not evaluate the well-known weakest zone of welded joint - coarse-grained heat affected zone (CGHAZ). It is a zone, where, during fusion welding, maximum (peak) temperature(s) close and over $1300^{\circ} \mathrm{C}$ is reached (Fig. 1b). On such high temperatures heat-affected zone microstructure tends to overgrow [6,9], following formation of a quite large grains, which finally has for consequence significant drop in toughness. Here, importance of sufficient toughness become particularly important, because of sufficient resistance to crack initiation and growth [2, 6, 10].

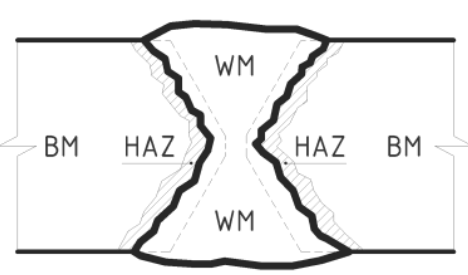

a) Welded joint zones: BM, HAZ, WM

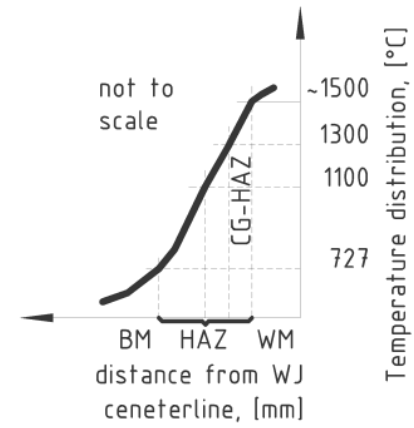

b) Approximate location of CG-HAZ

Fig. 1. Welded joint zones, including CG-HAZ regarding peak temperature distribution

Therefore, even one welding technology (e.g. procedure) may become qualified in well-known and standardized manner $[4,5]$, the process of qualification cannot evaluate the weakest welded joint zone - CG-HAZ. Regarding its size, in comparison to complete welded joint, weakening within CG-HAZ should not be neglected easily. However, even everyday welding engineering practice may not relay on sophisticated approaches and techniques, such as simulation of welding - thermo cycles; a more detailed investigation is required, at least to provide general sense of a weakening effect.

The following experimental procedure, as well as provided analysis, is one [6] of a possible approaches [10] to gain reasonable sense about intensity and distribution of a welded joints weakening within HAZ / CG-HAZ.

\section{Performed experiment}

Set of welded joints were performed using gas metal arc welding (GMAW) on two HSS, S690QL and S890QL, both delivered in accordance to EN 10025-6. The general welding parameters are shown on Tab. 1, while the appearance of welded joints macro-sections are shown on Fig. 2.

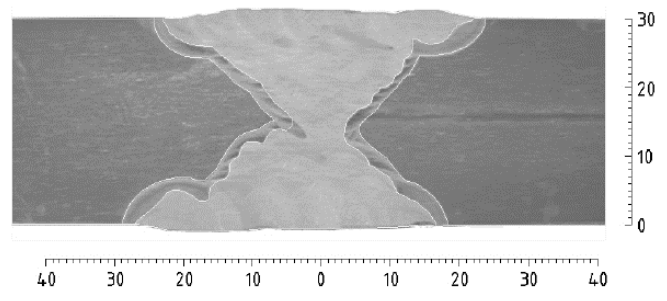

a) S690QL, 30mm

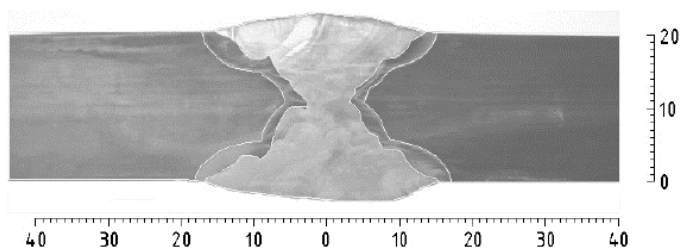

b) S890QL, 20mm

Fig. 2. Appearance of welded joints macro-sections [6] 


\begin{tabular}{|c|c|c|c|c|c|}
\hline HSS & Welding process & Thickness & Preheating & $\mathrm{t}_{8 / 5}$ & Filler Metal acc. to EN 12534 \\
\hline S690QL & GMAW & $30 \mathrm{~mm}$ & $200{ }^{\circ} \mathrm{C}$ & $6-8 \mathrm{~s}$ & G 69 5 M Mn 3 Ni 1 Cr Mo \\
\hline S890QL & GMAW & $20 \mathrm{~mm}$ & $150{ }^{\circ} \mathrm{C}$ & $6-7 \mathrm{~s}$ & $\mathrm{G} 896 \mathrm{M} \mathrm{Mn} \mathrm{4} \mathrm{Ni} 2 \mathrm{Cr} \mathrm{Mo}$ \\
\hline
\end{tabular}

Table 1. General welding parameters

Beside real welds on both HSS, a sufficient number of specimens, 10x10x50 mm from both HSS were prepared for welding - thermo cycle simulation on thermo-mechanical simulator "SmithWeld".

Those specimens were simulated with previously calculated thermos-cycles, using application "Thermocycle t85" (according to welding parameters shown on Tab. 1; e.g. preheat temperature and $t_{8 / 5}$ ), which correspond to CG-HAZ, e.g. with peak temperature $1300{ }^{\circ} \mathrm{C}$. Appearance of samples before, during and after welding thermo-cycle simulation are shown on Fig. 3.

The simulated samples were used for testing of hardness and impact toughness; while they actually represent the weakest zone of welded joint within heat-affected zone (HAZ).

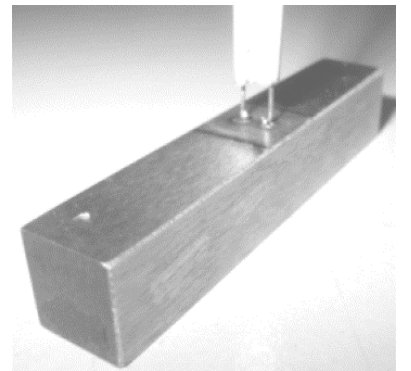

a) before simulation

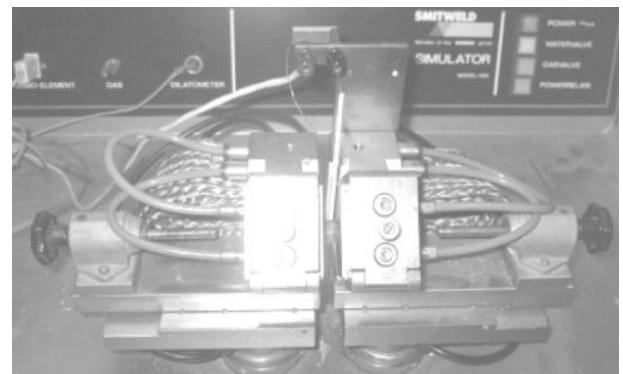

b) during simulation

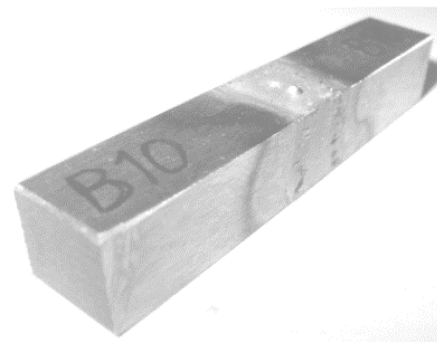

c) after simulation

Fig. 3. Appearance of simulated specimens [6]

Sampling of test specimens for tensile and impact toughness are taken as shown on Fig. 4, including spots for hardness testing on welded joints macro-sections.

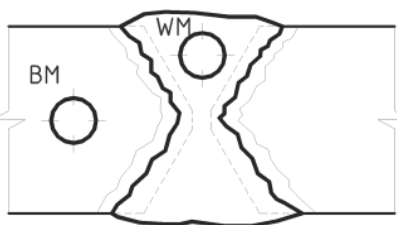

a) Tensile specimens for BM and WM; round transverse specimens were used.

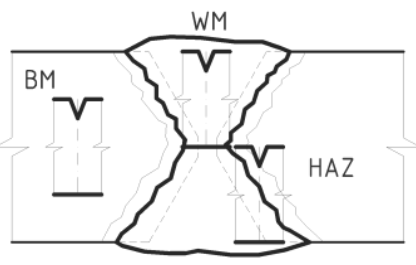

b) Initial notch for BM, WM and HAZ for impact toughness specimens;

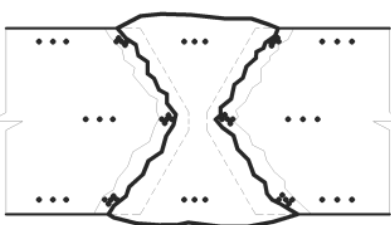

c) Hardness testing spots across welded joint macro-section (BM, HAZ, WM)

Fig. 4. Approximate sampling location for mechanical testing of real welded joints

All predicted mechanical testing were performed at room temperature, e.g. $20^{\circ} \mathrm{C}$; and in accordance to:

- $\quad$ EN 10002-1 and EN 895, for tensile testing of base metal (BM) and weld metal (WM).

- EN 10045-1 for impact toughness (or general toughness) testing of base metal (BM), heat-affected zone (HAZ) and weld metal (WM).

- EN 1043-1 for hardness testing HV10 (Vickers method) of welded joints macro-section (including all three zones: BM, HAZ and WM).

\section{Acquisition of mechanical properties}

Tab. 2 and 3 shows acquired experimental results, i.e. general ranges, of tested mechanical properties for both HSS; while only the shaded cells values were calculated based on relationship provided in Fig. 5 .

Obviously, from Tab. 2 and 3; high hardness has for consequence high strength and low toughness (as well as ductility); and vice-versa. Therefore, while considering generalised linear theoretical relationship [6] between hardness (HV10), strength $\left(\mathrm{R}_{\mathrm{m}}\right)$ and toughness $(\mathrm{KV})$; the following relationship (regression) analysis were performed (Fig. 5). 


\begin{tabular}{|c|c|c|c|c|}
\hline \multirow{2}{*}{$\begin{array}{c}\text { Mechanical } \\
\text { property }\end{array}$} & \multicolumn{4}{|c|}{ Tested welded joint zone } \\
\cline { 2 - 5 } & BM & HAZ & CG-HAZ & WM \\
\hline $\begin{array}{c}\text { Strength / Yield } \\
\text { stress, } \mathrm{R}_{\mathrm{p} 0,2} \text { [MPa] }\end{array}$ & $745-780$ & - & - & $695-720$ \\
\hline $\begin{array}{c}\text { Strength / Tensile } \\
\text { strength, } \mathrm{R}_{\mathrm{m}} \text { [MPa] }\end{array}$ & $857-898$ & 1020 & 1193 & $770-779$ \\
\hline Ductility, A [-] & $0,133-0,159$ & - & - & $0,144-0,164$ \\
\hline Hardness, HV10 & $262-283$ & $270-421$ & 413 & $254-274$ \\
\hline $\begin{array}{c}\text { Impact toughness, } \\
\text { KV [J] @ 20 }\end{array}$ & $184-212$ & $184-187$ & $85-94$ & $114-171$ \\
\hline
\end{tabular}

Table 2. Acquired mechanical properties for HSS, S690QL [6]

\begin{tabular}{|c|c|c|c|c|}
\hline \multirow{2}{*}{$\begin{array}{c}\text { Mechanical } \\
\text { property }\end{array}$} & \multicolumn{4}{|c|}{ Tested welded joint zone } \\
\hline & BM & HAZ & CG-HAZ & WM \\
\hline $\begin{array}{c}\text { Strength / Yield } \\
\text { stress, } R_{p 0,2}[\mathrm{MPa}]\end{array}$ & 935-962 & - & - & $878-915$ \\
\hline $\begin{array}{l}\text { Strength / Tensile } \\
\text { strength, } \mathrm{R}_{\mathrm{m}}[\mathrm{MPa}]\end{array}$ & $1007-1024$ & 1129 & 1247 & 963-984 \\
\hline Ductility, A [-] & $0,121-0,131$ & - & - & $0,138-0,157$ \\
\hline Hardness, HV10 & $327-351$ & $322-455$ & 434 & $317-351$ \\
\hline $\begin{array}{l}\text { Impact toughness, } \\
\mathrm{KV}[\mathrm{J}] @ 20^{\circ} \mathrm{C}\end{array}$ & $147-168$ & $135-145$ & $54-59$ & $99-108$ \\
\hline
\end{tabular}

Table 3. Acquired mechanical properties for HSS, S890QL [6]

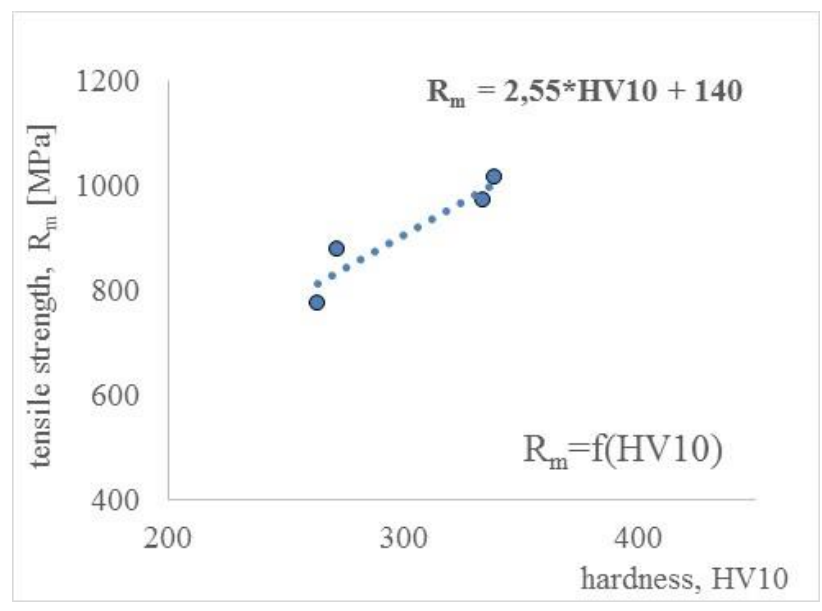

a) hardness vs. strength

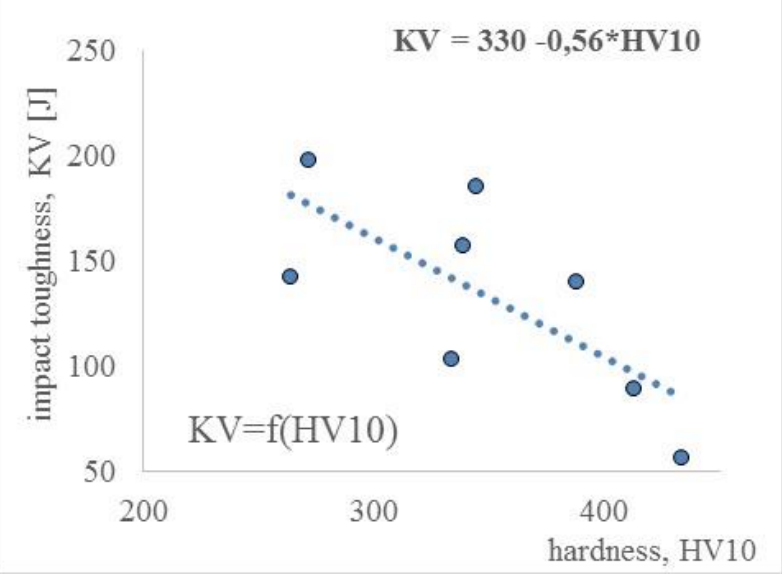

b) hardness vs. impact toughness

Fig. 5. Mechanical properties relationship(s)

\section{Results analysis}

Based on results, for $\mathrm{R}_{\mathrm{m}}, \mathrm{HV} 10$ and KV, provided in Tab. 2 and 3, the analysis (Fig. 6) of mechanical properties distribution is performed across one side of welded joint (e.g. right-hand of macro-section). However, it is reasonable to predict symmetry of mechanical properties distribution perpendicular to the butt welded joint axis.

Distance in [mm] of each zone (CG-HAZ, HAZ) from welded joint centre-line (e.g. c/l; which correspond to weld metal zone, WM) is determined from macro-section measurement (Fig. 2a and 2b). Actually, if considered on midthickness; the distances from WM (c/l) of CG-HAZ and HAZ are approximately $6 \mathrm{~mm}$ and $8 \mathrm{~mm}$ for S690QL; 5mm and $7 \mathrm{~mm}$ for S890QL; respectively.

The distance between HAZ (rest of HAZ with peak temperatures less than $1100^{\circ} \mathrm{C}$ ) and CG-HAZ is based on assumption that temperature distribution (according to Fig. 1b) is linear within HAZ. Actually, the width of CG-HAZ is $1,5-2,0 \mathrm{~mm}$ on both HSS welded joints; based on theoretical assumption [6] that CG-HAZ is located between $1100-$ $1500^{\circ} \mathrm{C}$ (Fig. 1b), with its peak on the $1300^{\circ} \mathrm{C}$. 


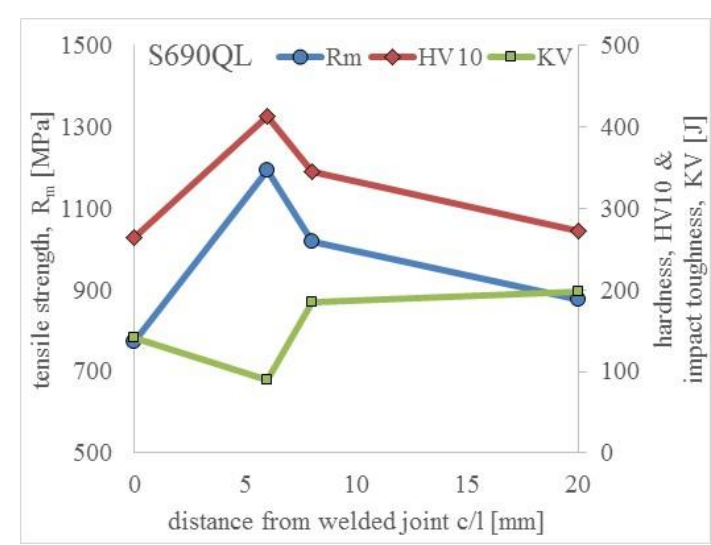

a) HSS, S690QL

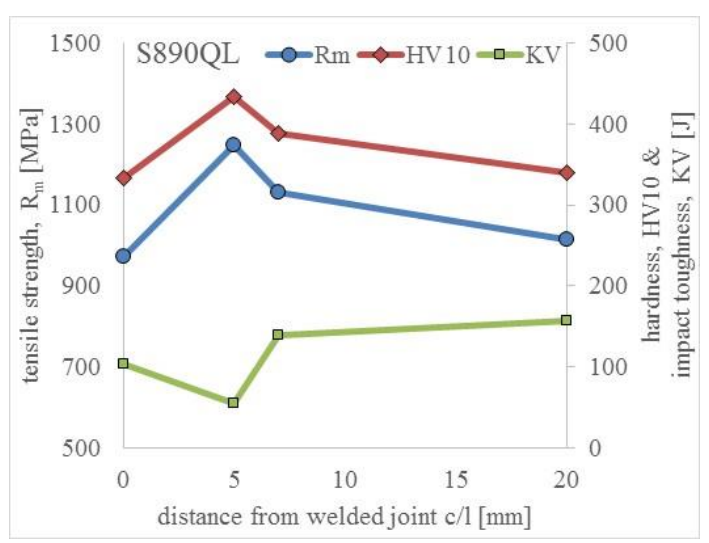

b) HSS, S890QL

Fig. 6. Distribution of mechanical properties across welded joints macro-sections

Finally, according to design requirements [4,5], that reference value for further comparison analysis are properties of a base metal (BM); than we can conclude mismatching of mechanical properties as shown in Tab. 4.

\begin{tabular}{|c|c|c|c|c|}
\hline \multirow{2}{*}{$\begin{array}{c}\text { Mechanical } \\
\text { property }\end{array}$} & \multicolumn{4}{|c|}{ Mismatch of mechanical properties in comparison to base metal (BM) } \\
\cline { 2 - 5 } & $\mathrm{BM}$ & $\mathrm{HAZ}$ & CG-HAZ & WM \\
\hline & & (overmatching) & (overmatching) & (undermatching) \\
Strength & 1 & 1,16 for S690QL & 1,36 for S690QL & 0,88 for S690QL \\
& & 1,11 for S890QL & 1,23 for S890QL & 0,96 for S890QL \\
\hline & & (overmatching) & (overmatching) & (undermatching) \\
Hardness & 1 & 1,27 for S690QL & 1,52 for S690QL & 0,97 for S690QL \\
& & 1,14 for S890QL & 1,28 for S890QL & 0,98 for S890QL \\
\hline & & (undermatching) & (undermatching) & (undermatching) \\
Toughness & \multirow{2}{*}{1} & 0,93 for S690QL & 0,45 for S690QL & 0,72 for S690QL \\
& & 0,89 for S890QL & 0,37 for S890QL & 0,66 for S890QL \\
\hline
\end{tabular}

Table 4. Mismatch of mechanical properties across welded joint

Simply, undermatching (grey shaded cells in Tab. 4) may be considered as weakening of particular welded joint zone relative to the base metal; e.g. regarding strength, the weld metal (WM) is weaker in comparison to the base metal (BM) for $12 \%$ in the case of S690QL steel welded joint; or 4\% weaker in the case of S890QL steel.

\section{Conclusion}

A problem of welded joint mechanical properties distribution, regarding level of mismatching effect, in real welds is present and it cannot be evaluated using standardised qualification procedures. Therefore, more detailed and sophisticated approach is required, at least by mean of preparation of additional specimens using simulation of welding - thermo cycle(s) of theoretically known weakest zone - coarse grained heat affected zone (CG-HAZ).

The presented investigation show one limited approach, mostly regarding selected high-strength steel(s) (its nominal strength values), and simulation used only for further evaluation of hardness and toughness. Also, it is possible to use presented simulation technique (as a mean of specimen's preparation) for any further mechanical testing; such as for strength testing which is not done within this research. For the purpose of this investigation, the strength of simulated CG-HAZ was recalculated (Tab. 2 and 3) based on the mechanical properties relationship analysis (Fig 5).

However, the provided investigation show clearly that the higher is strength of one high-strength steel (HSS) the lower ductility and toughness are. Beside that; welding may influence significantly a mechanical properties of welded joint.

Generally speaking, mismatching of properties are always present; but further important question arise: how intense mismatching effect is in major welded joint zones?! However, from a point of design requirements, a particular attention should be drawn to mismatching of hardness and toughness.

Thus, in the case of investigated high-strength steel's (HSS) GMAW welded joints, with the nominal strength in the range of 690-890 MPa; there is a significant undermatching of toughness; as well as overmatching of hardness; within heat-affected zone (HAZ).

The hardness overmatching goes from $+(14-52) \%$, with its maximum value within coarse-grained heat-affected zone (CG-HAZ). Contrary, the toughness undermatching goes from -(7-63)\%, with its maximum weakening within coarsegrained heat-affected zone (CG-HAZ). 
Such degraded toughness may have for consequence notable loss of welded joint crack resistance. In addition, while so weakened zone of welded joint represent up to $40 \%$ of complete heat-affected zone (HAZ) width, it should not be neglected easily.

Finally, it is suggested that further studies and investigation(s) include wider range of structural steels; for example from $420 \mathrm{MPa}$, up to $1300 \mathrm{MPa}$; and more use of simulation technique. Actually, as long as simulation of welding thermo cycles can be used for any peak temperature within $\mathrm{HAZ}$ (not only for CG-HAZ, $1300^{\circ} \mathrm{C}$ ), it can provide more precise analysis of mechanical properties distribution.

\section{References}

[1] Janicek S.; Jirkova H.; Kucerova L. \& Masek B. The behaviour of low-alloy high-strength steel after different types of processing for dynamic load, Annals of DAAAM for 2011 \& Proceedings of the 22nd International DAAAM Symposium, Volume 22, No. 1, ISSN 1726-9679, ISBN 978-3-901509-83-4, Vienna, Austria, EU, 2011.

[2] Hajro I.; Burzic Z.; Kapor J. N.; Kokelj T. Experimental investigation of high-strength structural steel welds. Strojniski vestnik - Jounral of Mechanical Engineering 58(2012)6, p422-428, Slovenia, 2012.

[3] Kolarik L.; Kolarikova M.; Vondrous P. \& Hrabina R. The choice of parameters for welding of steel S355NL. Annals of DAAAM for 2012 \& Proceedings of the 23rd International DAAAM Symposium, Volume 23, No. 1, ISSN 2304-1382, ISBN 978-3-901509-91-9, Vienna, Austria, EU, 2012.

[4] ISO 15614-1, Specification and qualification of welding procedures for metallic materials - Welding procedure test - Part 1: Arc and gas welding of steels and arc welding of nickel and nickel alloys, ISO - International Organization for Standardization, 2017.

[5] ASME Boiler and Pressure Vessel Code - Section IX, Welding, Brazing, and Fusing Qualifications, ASME American Society of Mechanical Engineers, 2017.

[6] Hajro I (2010). Research of ductile tearing and fracture resistance of quenched and tempered high-strength steel's welded joints, Ph.D. Dissertation, Department for manufacturing technologies, Faculty of Mechanical Engineering - University of Sarajevo, Bosnia and Herzegovina.

[7] Hot rolled Steel Plates, Sheets and Coils - Processing of material - Welding, Ruukki / Ruukki Metals Oy, Helsinki, Finland, 2017.

[8] High-strength heavy plates - Weight savings combined with excellent weldability, VoestAlpine Grobblech GmbH, Austria, 2008.

[9] Holub L.; Dunovsky J.; Kovanda K. \& Kolarik L. SAW - Narrow Gap Welding CrMoV Heat-Resistant Steels Focusing to the Mechanical Properties Testing. Procedia Engineering - Conference Proceedings of the 25th International DAAAM Symposium on Intelligent Manufacturing and Automation, Volume 100-2015, ISSN 18777058, ScienceDirect.

[10] Inoslav R.; Gubeljak N. \& Praunseis Z. The fracture behaviour of global / local mi-matched weld joints provided on HSLA steels. Materials and Technology 35(3-4)89(2001). ISSN 1580-2949. Slovenia, EU, 2001. 